\section{A comparative study of patient-controlled epidural fentanyl and single dose epidural morphine for post- Caesarean analgesia}

Patrick Y.H. Yu MD FRCPC,

David R. Gambling MD BS DRCOG FRCPC
In a prospective, randomized, double-blinded study, 23 patients who had undergone Caesarean delivery under epidural anaesthesia were assessed to evaluate the effectiveness of patientcontrolled epidural analgesia (PCEA) with fentanyl compared with a single dose of epidural morphine for postoperative analgesia. Group $A(n=11)$ received epidural fentanyl $100 \mu \mathrm{g}$ intraoperatively, then self-administered a maximum of two epidural fentanyl boluses $50 \mu \mathrm{g}\left(10 \mu \mathrm{g} \cdot \mathrm{ml}^{-1}\right)$ with a lockout period of five minutes for a maximum of two doses per hour. Group $B(n=11)$ received a single bolus of epidural morphine $3 \mathrm{mg}$ $\left(0.5 \mathrm{mg} \cdot \mathrm{ml}^{-1}\right)$ intraoperatively and received the same instructions as Group $A$ but had their PCA devices filled with $0.9 \%$ $\mathrm{NaCl}$. Patients were assessed up to $24 \mathrm{hr}$ for pain, satisfaction with pain relief, nausea and pruritus using visual analogue scales (VAS). The treatments for inadequate analgesia, nausea and pruritus as well as time to first independent ambulation were recorded. The ventilatory response to carbon dioxide challenge was measured at four and eight hours. Pain relief, satisfaction with pain relief, and the use of supplemental analgesics were similar in both groups. The mean $24 \mathrm{hr}$ dose of epidural

\section{Key words}

ANAESTHESIA: obstetric;

ANAESTHETIC TECHNIQUES: epidural, lumbar;

ANALGESIA: postoperative;

ANALGESICS: fentanyl, morphine;

EQUIPMENT: patient-controlled analgesia.

From the Departments of Anaesthesia, Grace Hospital, and University of British Columbia, Vancouver, British Columbia.

This work was presented in part at the Annual Meeting of the Canadian Anaesthetists' Society, June 9-13, 1989 in

Ottawa, Ontario.

Address correspondence to: Dr. Patrick Y.H. Yu, Department of Anaesthesia, Royal Columbian Hospital, 330

East Columbian Street, New Westminster, British Columbia, Canada V3L 3W7.

Accepted for publication 1lth February, 1993. fentanyl used by group A patients was $680 \mu \mathrm{g}$. Pruritus was less common in Group A patients at the 8 and $24 \mathrm{hr}$ observation periods $(P<0.0125)$. Both groups experienced the same degree of nausea and clinically unimportant respiratory depression. We conclude that PCEA with fentanyl provides analgesia equal to a single dose of epidural morphine and may be suitable for patients who have experienced considerable pruritus after epidural morphine adminstration.

Cette étude randomisée et à double-aveugle vise à évaluer l'efficacité de l'épidurale auto-contrôlée au fentanyl comparée à une seule dose de morphine épidurale pour l'analgésie postopératoire. Vingt-trois opérées pour césarienne sont réparties en deux groupes: le group $A(n=11)$ a reçu une épidurale avec fentanyl $100 \mu \mathrm{g}$ pendant lintervention puis s'administre au pousse-seringue PCA deux bolus de fentanyl $50 \mu \mathrm{g}$ (10 $\mu \mathrm{g} \cdot \mathrm{ml}^{-1}$ ) avec un intervalle de sécurité de cinq minutes pour un maximum de deux doses à l'heure. Le groupe $B(n=11)$ a reçu un seul bolus épidural de morphine $3 \mathrm{mg}\left(0,5 \mathrm{mg} \cdot \mathrm{ml}^{-1}\right)$ pendant lintervention, obtient les mêmes directives que le groupe $A$ mais ne s'administre que du soluté physiologique par le pousse-seringue PCA. Lévaluation se continue jusqu'à 24 heures sur des échelles visuelles analogiques de la douleur, du degré de satisfaction, des nausées et vomissements, et du prurit. On enregistre le traitement de l'analgésie insuffisante, des nausées et du prurit, ainsi que le moment de l'autonomie ambulatoire. La réponse ventilatoire au dioxyde de carbone est mesurée à la quatrième et à la huitième heures. Le soulagement, la satisfaction et la supplémentation par des analgésiques sont les mêmes pour les deux groupes. La dose moyenne pour 24 heures de fentanyl épidural utilisée par le groupe $A$ est de $680 \mu \mathrm{g}$. Le prurit est moins fréquent dans ce groupe aux périodes d'observation de huit et 24 heures ( $P$ $<0,0125)$. Les deux groupes ont souffert au même degré de nausées et de dépression respiratoire cliniquement sans importance. Nous concluons que l'anesthésie épidurale auto-contrôlée au fentanyl produit une analgésie égale à celle de la morphine épidurale; cette technique pourrait être utilisée avec avantages 
chez la patiente qui a déjà souffert d'un prurit important après l'administration de morphine épidurale.

Epidural opioids are successfully used in many clinical settings to provide postoperative analgesia by either intermittent bolus, continuous infusion or patient-controlled device. Epidural morphine, given as a single bolus, provides a long duration of action but can be associated with considerable nausea, pruritus, and a small risk of delayed respiratory depression. ${ }^{1,2}$ Epidural morphine 3 $\mathrm{mg}$ has been reported as the optimal dose for postCaesarean analgesia. ${ }^{3}$ Fentanyl is more lipophilic than morphine and therefore offers the advantage of a reduction in side effects including less risk of delayed respiratory depression. ${ }^{4-6}$ Rapid absorption from the epidural space makes fentanyl suitable for use by a patientcontrolled technique because of its more rapid onset time and shorter duration of action. Epidural fentanyl $50 \mu \mathrm{g}$ has been described as the minimum reliably effective dose for post-Caesarean analgesia, ${ }^{5}$ whereas epidural fentanyl $100 \mu \mathrm{g}$ has been reported to provide analgesia without undesirable side effects. ${ }^{7}$ The purpose of this study was to test in a prospective, randomized, and double-blind manner, the effectiveness of patient-controlled epidural analgesia (PCEA) using fentanyl compared to a single dose of epidural morphine in patients who have undergone lower segment Caesarean delivery.

\section{Methods}

After the study was approved by the ethics committees of the hospital and university, informed consent was obtained from ASA I or II women presenting for elective lower segment Caesarean delivery under epidural anaesthesia. Epidural catheterization was performed in a standard manner after adequate intravenous hydration. The lumbar interspace at the 2-3 or 3-4 level was employed and the epidural catheter inserted through a 17 gauge Tuohy needle. Epidural anaesthesia was achieved using increments of lidocaine hydrocarbonate $1.73 \%$ with epinephrine $1: 400,000$, titrated to an upper sensory block of $\mathrm{T}_{4}$. Intraoperatively, inadequate anaesthesia was supplemented with additional epidural lidocaine and/or $i v$ fentanyl $12.5-25 \mu \mathrm{g}$. Patients were randomly assigned to one of two treatment groups. Group A received epidural fentanyl $100 \mu \mathrm{g}$ diluted to $6 \mathrm{ml}$ volume with $0.9 \% \mathrm{NaCl}$, $20 \mathrm{~min}$ after delivery of the newborn. The epidural catheter was left in situ for $24 \mathrm{hr}$ post-delivery, and was attached to a PCA device on arrival to the PACU. Women in Group B received epidural morphine $3 \mathrm{mg}(0.5$ $\mathrm{mg} \cdot \mathrm{ml}^{-1}$ ), $20 \mathrm{~min}$ after delivery. They also had the epidural catheter left in situ attached to a patient controlled analgesia (PCA) device in the PACU. In Group A they had the ability to self-administer a maximum of fentanyl $100 \mu \mathrm{g}\left(10 \mu \mathrm{g} \cdot \mathrm{ml}^{-1}\right)$ every hour, in two increments. Women in Group B were given the same instructions for postoperative pain relief but the PCA devices were filled with $0.9 \% \mathrm{NaCl}$. Group assignment, and medication preparations were performed by an anaesthetist who was otherwise not associated with the study. The patients, attending nurses and physicians, and investigators were unaware of treatment group assignment.

The PCA device used was a Pharmacia Deltec(T) Model 5200 PXC Computerized Ambulatory Drug Delivery Pump (Pharmacia (Canada)) which delivers a maximum bolus of $5 \mathrm{ml}$. The pump was programmed to deliver an epidural fentanyl $50 \mu \mathrm{g} \cdot 5 \mathrm{ml}^{-1}$ bolus with a lockout period of five minutes for a maximum of two boluses per hour. The patients were instructed to make an initial demand when analgesia was required but to repeat the demand five minutes later to obtain the full dose (i.e., fentanyl $100 \mu \mathrm{g}$ in $10 \mathrm{ml}$ ). They were informed to expect maximal pain relief within $15-20 \mathrm{~min}$ of the second demand.

On returning to the ward, patients could request additional analgesic supplements of oral acetaminophen 325 $\mathrm{mg}$ with codeine $30 \mathrm{mg}$ or im meperidine $50-100 \mathrm{mg}$ every three to four hours as required.

Nausea was treated with im metoclopramide $10 \mathrm{mg}$ every six hours as required and pruritus was treated with im naloxone $0.2 \mathrm{mg}$ every three hours as required.

Patients were assessed at 2, 4, 8, and $24 \mathrm{hr}$ after the administration of the initial dose of study drugs. At these time intervals the following data were collected:

1 Ten $\mathrm{cm}$ visual analog scales (VAS) for pain, satisfaction with pain relief, nausea, and pruritus.

2 The number of patient demands for epidural analgesia. 3 The number of treatments for pain, itch or nausea.

4 Time to first independent ambulation.

The ventilatory response to carbon dioxide challenge $\left(5 \% \mathrm{CO}_{2}\right.$ in air) was measured before surgery and at four and eight hours after receiving the first dose of epidural opioid. Patients had their expired minute volume measured with a Wrights' respirometer while breathing room air. All patients wore a nose clip and were instructed about the test beforehand. Subsequently they inhaled $5 \% \mathrm{CO}_{2}$ through a non-rebreathing apparatus. End tidal $\mathrm{CO}_{2}$ was measured (Ohmeda $5200 \mathrm{CO}_{2}$ monitor) and after it stabilized, expired minute volume was again measured.

The sample size was estimated before the study commenced, on the basis of detecting a $2 \mathrm{~cm} \pm \mathrm{SD}$ of 1.5 $\mathrm{cm}$ difference for VAS scores. A sample size of ten patients in each group provided a power of 0.8. Statistical analysis consisted of Student's $t$ test for interval data, Mann Whitney $U$ test for ordinal data or data with non- 
normal distribution, and two factor-repeated measures ANOVA was used for $\mathrm{CO}_{2}$ challenge test data. Post hoc analysis consisted of Newman Keul's test for multiple comparisons of the group and time factors and Student's $t$ tests with Bonferroni's correction were used to analyze between-group comparisons at each time point. Supplemental treatments for pain, itch or nausea were collapsed into counts and analyzed using $2 \times 2$ tables using Fisher's exact test. For VAS data and number of patient demands, a $P$ value $<0.0125$ was considered significant. A $P$ value $<0.0166$ was considered significant for $\mathrm{CO}_{2}$ challenge test data and the use of supplemental drugs for side effects. All other data were considered statistically significant at a $P$ value $<0.05$.

\section{Results}

Twenty-three patients enrolled in the study. One patient withdrew due to accidental dislodgment of her epidural catheter. Data for 22 patients were collected with 11 in each group. There were no differences with regard to age, height, parity, weight, dose of lidocaine required for epidural anaesthesia, amount of intraoperative supplemental medication, duration of surgery and maximum sensory level (Table I). Group A patients had a shorter time to first ambulation (mean: $18 \mathrm{vs} 22 \mathrm{hr}, P<0.05$ ).

The mean 24-hr dose of epidural fentanyl used by Group A patients was $680 \pm 180 \mu \mathrm{g}$, the result of 13.6 \pm 3.6 patient-demands. Of 158 patient-demands in Group A patients, 150 were successful in demanding two consecutive fentanyl $50 \mu \mathrm{g}$ boluses; whereas eight received only one bolus. In Group B patients, there was a mean of $3.2 \pm 2.3$ patient-demands throughout the study period. The number of patient-demands differed at all time points throughout the study except at the two-hour observation period (Table II). There were no differences between groups in terms of pain relief or patient satisfaction with pain relief at any of the observation periods.

Pruritus was less in Group A patients at 8 and 24 hr (Table III), but we observed no difference in the incidence of nausea or the use of naloxone or metaclopramide.

The $\mathrm{CO}_{2}$ challenge test data did not differ significantly between groups at any of the observation periods but minute ventilation was significantly reduced in both groups at four and eight hours compared to values obtained prior to surgery (Table IV). No cases of clinically significant respiratory depression were observed.

\section{Discussion}

This study demonstrated that PCEA with fentanyl after Caesarean delivery provides analgesia comparable with a single dose of epidural morphine $3 \mathrm{mg}$ with less pruritus. The incidence and severity of pruritus as repre-
TABLE I Demographic data (mean \pm SD)

\begin{tabular}{lccl}
\hline & $\begin{array}{l}\text { Group } A \\
n=11\end{array}$ & $\begin{array}{l}\text { Group } B \\
n=11\end{array}$ & P value \\
\hline Age (yr) & $31.8 \pm 4.9$ & $29.5 \pm 4.2$ & NS \\
Parity (median (range)) & $1(0-2)$ & $1(0-3)$ & NS \\
Height (cm) & $161 \pm 7$ & $163 \pm 6$ & NS \\
Weight (kg) & $77.7 \pm 16.6$ & $79.1 \pm 8.5$ & NS \\
Volume of lidocaine (ml) & $17 \pm 4$ & $17 \pm 3$ & NS \\
Duration of surgery (min) & $80 \pm 16$ & $71 \pm 16$ & NS \\
Maximum sensory level & & & \\
$\quad$ (median (range)) & $\mathrm{T}_{4}(2-5)$ & $\mathrm{T}_{4}(1-5)$ & NS \\
Time to ambulation (hr) & $18 \pm 8$ & $22 \pm 4$ & 0.037 \\
\hline
\end{tabular}

TABLE II Number of patient demands for epidural analgesia (median (range))

\begin{tabular}{llll}
\hline Time & Group $A$ & Group $B$ & $P$ value \\
\hline $2 \mathrm{hr}$ & $0(0-2)$ & $0(0-2)$ & NS \\
$4 \mathrm{hr}$ & $2(0-4)$ & $1(0-2)$ & 0.009 \\
$8 \mathrm{hr}$ & $3(2-4)$ & $0(0-2)$ & 0.0001 \\
$24 \mathrm{hr}$ & $8(4-12)$ & $1(0-4)$ & 0.0001 \\
Total & $14(8-20)$ & $3(0-7)$ & 0.0001 \\
\hline
\end{tabular}

TABLE III Median pruritus VAS scores (range) score of $10=$ maximum pruritus; $\mathrm{i}=$ incidence

\begin{tabular}{llll}
\hline Time & Group $A$ & Group B & Pvalue $^{*}$ \\
\hline $2 \mathrm{hr}$ & $0(0-4.5)$ & $0(0-5.3)$ & $\mathrm{NS}$ \\
& $\mathrm{i}=5$ & $\mathrm{i}=4$ & \\
$4 \mathrm{hr}$ & $0(0-8.2)$ & $4.6(0-9.8)$ & $\mathrm{NS}$ \\
& $\mathrm{i}=6$ & $\mathrm{i}=10$ & \\
$8 \mathrm{hr}$ & $0(0-2.1)$ & $4.3(0-7.8)$ & 0.0007 \\
& $\mathrm{i}=5$ & $\mathrm{i}=10$ & \\
$24 \mathrm{hr}$ & $0(0-16)$ & $5.0(0-9.5)$ & 0.0064 \\
& $\mathrm{i}=4$ & $\mathrm{i}=9$ & \\
\hline
\end{tabular}

*VAS ranking using Mann-Whitney $\mathrm{U}$ test.

TABLE IV Ventilatory response to $5 \% \mathrm{CO}_{2}$ in air, $\mathrm{L} \cdot \mathrm{min}^{-1}$ (mean $\pm \mathrm{SD}$ )

\begin{tabular}{llrrl}
\hline & & Group $A$ & \multicolumn{1}{c}{ Group B } & $P$ value \\
\hline Before & & & & \\
surgery & Air & $8.3 \pm 3.2$ & $9.0 \pm 3.1$ & NS \\
& $5 \% \mathrm{CO}_{2}$ & $13.7 \pm 5.4$ & $14.5 \pm 4.4$ & NS* \\
4 hour & $\mathrm{Air}$ & $7.6 \pm 2.7$ & $8.7 \pm 3.5$ & NS \\
& $5 \% \mathrm{CO}_{2}$ & $12.0 \pm 4.3$ & $11.8 \pm 2.8$ & $\mathrm{NS}^{*}$ \\
8 hour & $\mathrm{Air}$ & $7.1 \pm 3.4$ & $9.8 \pm 3.6$ & $\mathrm{NS}^{*}$ \\
& $5 \% \mathrm{CO}_{2}$ & $11.6 \pm 4.7$ & $11.6 \pm 3.4$ & $\mathrm{NS}^{*}$ \\
\hline
\end{tabular}

*Minute ventilation with $5 \% \mathrm{CO}_{2}$ is decreased at four hours and eight hours in both groups compared with before surgery by Neuman-Keul's test. 
sented by VAS scores were less in Group $A$ at the 8 and $24 \mathrm{hr}$ observation periods. Pruritus occurred in 10 out of 11 women who received morphine which is consistent with the incidence reported in the literature. $3,8,9$ Single bolus epidural fentanyl has been reported to produce a lower incidence of pruritus; ${ }^{7,10}$ however, this has been associated with inadequate duration of analgesia. In Group B, three patients complained of mild pruritus (only one VAS score $>2$ ) for the entire 24-hr study period. Five other patients complained intermittently of mild to moderate pruritus (highest VAS score $=4.5$ ).

The analgesic potency of epidural fentanyl compared with morphine has been calculated to be about ten. " This study did not attempt to compare equipotent doses of epidural fentanyl with epidural morphine since $3 \mathrm{mg}$ of morphine would be equal to $300 \mu \mathrm{g}$ of fentanyl and most clinical experience has been in doses of between $50-150 \mu \mathrm{g}$. Over the study period, patients used on average $28.4 \mu \mathrm{g} \cdot \mathrm{hr}^{-1}$ of epidural fentanyl. Recently, a study of PCEA with fentanyl for post-thoracotomy pain showed an average fentanyl requirement of $93 \mu \mathrm{g} \cdot \mathrm{hr}^{-1}{ }^{12}$ This higher rate of fentanyl consumption can be explained by their use of a variable background infusion rate and a shorter lockout interval of $15 \mathrm{~min}$. In addition, pain levels are probably greater in patients following thoracotomy than after Caesarean birth.

We selected the epidural fentanyl dosing regimen by default. Our aim was to have patients self-administer fentanyl $100 \mu \mathrm{g}$ in a $10 \mathrm{ml}$ volume. The PCA pump that we used was unable to deliver this volume in a single delivery. Therefore, we devised a method whereby the full dose could be self-administered in two divided doses as described in the methods section. Most patients were compliant with the instruction to demand two consecutive fentanyl boluses. One patient in one instance did not demand a second bolus despite inadequate analgesia. In another seven instances, five patients demanded only one fentanyl $50 \mu \mathrm{g}$ bolus despite our instructions because they had achieved satisfactory analgesia.

Group A women were able to ambulate earlier despite no differences in analgesia. The ability to ambulate may be more as a consequence of other factors that were not measured, for instance, patient motivation. In contrast, Yarnell ${ }^{13}$ showed that earlier ambulation was associated with better analgesia in women who received PCEA using meperidine compared to intermittent im meperidine. That study was unfortunately not double-blind and therefore was subject to both observer and patient bias.

The inability to demonstrate a larger difference between the treatment groups may have been due to inadequate sensitivity in the use of VAS scores. Recently, the development of a combined symptom-therapy score has been shown to be more sensitive than VAS scores at as- sessing nausea during PCA using iv morphine. ${ }^{14}$ Clinical differences between groups might have been more evident in this study by using a similar score.

Some patients did not enjoy having an epidural catheter in situ. It was not painful but they were aware of it. One potential problem of an indwelling epidural catheter is the possibility of catheter migration or dislodgment. In our study, we had one epidural catheter that migrated into a subcutaneous position. That patient had good analgesia initially but gained no relief of pain with subsequent demands.

Patient-controlled epidural fentanyl administration was associated with a reduced ventilatory response to $\mathrm{CO}_{2}$. This effect was not clinically significant and was consistent with that found in patients receiving a continuous epidural infusion of fentanyl at $1 \mu \mathrm{g} \cdot \mathrm{kg} \cdot \mathrm{min}^{-1}$ after orthopaedic surgery of the knee. ${ }^{15}$ We did not observe any patient to be excessively somnolent and all patients were nursed in a regular ward setting. The sample size in this study was too small to comment on the safety of PCEA with fentanyl. Recently, Brockway et al. reported a case of profound respiratory depression occurring $100 \mathrm{~min}$ after the epidural administration of fentanyl $100 \mu \mathrm{g}$ to a woman undergoing Caesarean section. ${ }^{16}$ This was associated with a higher than normal sensory block $\left(\mathrm{C}_{4}\right)$ using a mixture of fentanyl $100 \mu \mathrm{g}$ diluted in $0.5 \%$ bupivacaine $20 \mathrm{ml}$. The authors postulated that the fentanyl bupivacaine solution may have diffused to the respiratory centre in the fourth ventricle causing respiratory depression. This should alert the anaesthetist to the possibility of delayed respiratory depression using epidural fentanyl. Our patients stayed a minimum of two hours in the PACU after receiving their intraoperative dose of epidural opioid and thus unusual reactions would have been noticed. Postoperatively, two boluses of epidural fentanyl, $50 \mu \mathrm{g}$ in $5 \mathrm{ml}$, were given which is less likely to produce the spread of fentanyl high enough to reach the fourth ventricle than a single $20 \mathrm{ml}$ bolus. Nevertheless, until larger clinical series are available, this practice should be approached with caution with rigid protocols in place for monitoring patients.

Another drawback to the PCEA with fentanyl is the increase in cost associated with its use when compared with a single dose of epidural morphine. For Group A the cost of supplies for this study was Can\$57.15 per patient (appendix) whereas in Group B the cost per patient is Can $\$ 7.57$ for one ampoule of epidural morphine $0.5 \mathrm{mg} \cdot \mathrm{m}^{-1} \times 10 \mathrm{ml}$. This cost difference should be analyzed relative to total hospital charges and some centers may be able to provide PCEA cheaper than that quoted above.

In conclusion, the present study shows that patientcontrolled epidural administration of fentanyl provides 
women with comparable analgesia to single bolus epidural morphine for $24 \mathrm{hr}$ following Caesarean delivery. Patients were satisfied with titrating their own analgesia and had less pruritus with fentanyl. This method of analgesia may be suitable for the motivated patient with a history of severe pruritus after epidural morphine administration.

\section{Acknowledgments}

The authors are grateful to Pharmacia Deltec for providing the PCA device. We also thank Ms. Pamela Merrick for her assistance with statistical analysis.

\section{Appendix}

Group A patients: cost analysis

PCA pump purchase price $=\$ 4000$; amortized over three years $=\$ 3.65$ per day

$\begin{array}{lr}\text { Estimate usage of one patient every } & \\ \quad \text { two days: cost per patient } & \$ 7.30 \\ \text { Disposable medication cassette } & 32.75 \\ \text { One } 250 \mathrm{ml} 0.9 \% \mathrm{NaCl} \text { for diluent } & 1.20 \\ \text { One } 20 \mathrm{ml} \text { ampoule fentanyl } 50 \mu \mathrm{g} \cdot \mathrm{ml}^{-1} & 15.90 \\ \text { Total cost per patient } & \$ 57.15\end{array}$

\section{References}

1 Cousins MJ, Mather LE. Intrathecal and epidural administration of opioids. Anesthesiology 1984; 61: 276-310.

2 Fuller JG, McMorland GH, Douglas MJ. Epidural morphine for analgesia after Caesarean section: a report of 4880 patients. Can J Anaesth 1990; 37: 636-40.

3 Writer WDR. Epidural morphine for post-Caesarean analgesia. Can J Anaesth 1990; 37: 608-12.

4 White MJ, Berghausen EJ, Dumont SW, et. al. Side effects during continuous epidural infusion of morphine and fentanyl. Can J Anaesth 1992; 39: 576-82.

5 Naulty JS, Datta S, Ostheimer GW, Johnson MD, Burger $G A$. Epidural fentanyl for postcesarean delivery pain management. Anesthesiology 1985; 63: 694-8.

6 Welchew $E A$. The optimum concentration for epidural fentanyl. Anaesthesia 1983; 38: 1037-41.

7 Robertson K, Douglas MJ, McMorland GH. Epidural fentanyl with and without epinephrine for post-Caesarean section analgesia. Can Anaesth Soc J 1985; 32: 502-5.

8 Harrison DM, Sinatra R, Morgese L, Chung $J H$. Epidural narcotic and patient-controlled analgesia for postCesarean section pain relief. Anesthesiology 1988; 68: 454-7.

9. Writer WDR, Hurtig JB, Edelist G, et al. Epidural morphine prophylaxis of postoperative pain: report of a double-blind multicentre study. Can Anaesth Soc J 1985; 32: $330-8$.
10 Celleno D, Capogna G, Sebastiani M, et al. Epidural analgesia during and after Cesarean delivery. Comparison of five opioids. Reg Anesth 1991; 16: 79-83.

11 Chrubasik J, Wüst H, Schulte-Mönting J, Thon K, Zindler $M$. Relative analgesic potency of epidural fentanyl, alfentanil, and morphine in treatment of postoperative pain. Anesthesiology 1988; 68: 929-33.

12 Grant RP, Dolman JF, Harper JA, et al. Patientcontrolled lumbar epidural fentanyl compared with patientcontrolled intravenous fentanyl for post-thoracotomy pain. Can J Anaesth 1992; 39: 214-9.

13 Yarnell $R W$, Polis T, Reid GN, Murphy IL, Penning JP. Patient-controlled analgesia with epidural meperidine after elective cesarean section. Regional Anesth 1992; 17: 329-33.

14 Silverman DG, Freilich J, Sevarino FB, Paige D, Preble L, $O^{\prime} C o n n o r T Z$. Influence of promethazine on symptomtherapy scores for nausea during patient-controlled analgesia with morphine. Anesth Analg 1992; 74: 735-8.

15 Renaud B, Brichart JF, Clergue F, Chauvin M, Levron $J C$, Viars $P$. Ventilatory effects of continuous epidural infusion of fentanyl. Anesth Analg 1988; 67: 971-5.

16 Brockway MS, Noble DW, Sharwood-Smith GH, McClure $J H$. Profound respiratory depression after extradural fentanyl. Br J Anaesth 1990; 64: 243-5. 